\title{
Autoimmune hepatitis, Primary sclerosing cholangitis, and Non-alcoholic steatohepatitis cirrhosis may be more predisposed to the development of hepatocellular carcinoma
}

\section{Zohreh Khajehahmadi}

Hamadan University of Medical Sciences Medical School

Heidar Tavilani

Hamadan University of Medical Sciences Medical School

Jamshid Karimi

Hamadan University of Medical Sciences Medical School

Mohammad Rafiee

Zanjan University of Medical Sciences

Zahra Arab Sadeghabadi

Bu-Ali Sina University: Bu Ali Sina University

Roohollah Mohseni

Shahrekord University of Medical Science

Sina Mohagheghi ( $\square$ amr.mohaghegh@yahoo.com )

Hamadan University of Medical Sciences Medical School https://orcid.org/0000-0003-0388-8095

Research Article

Keywords: AMPK, Fatty Liver, Cirrhosis, AlH, p53

Posted Date: June 16th, 2022

DOI: https://doi.org/10.21203/rs.3.rs-1266028/v2

License: (c) (1) This work is licensed under a Creative Commons Attribution 4.0 International License. Read Full License 


\section{Abstract}

Background. The effect of cirrhosis etiology on the development of HCC is unclear. The study of the main indicators of cell proliferation and also apoptosis in cirrhotic tissues with different etiologies may declare which one of the cirrhosis etiologies more predispose to the development of HCC. The present study aimed to investigate the gene expression of p53, AMPK and pAMPK protein expressions and the AgNOR features in cirrhotic livers with different etiologies, livers with simple steatosis, and controls.

Methods. AMPK and pAMPK protein levels, p53 gene expression, and also AgNOR features were studied in livers with $\mathrm{NASH}(\mathrm{n}=15), \mathrm{HBV} / \mathrm{HCV}(\mathrm{n}=14), \operatorname{AlH}(\mathrm{n}=15), \operatorname{PSC}(\mathrm{n}=15)$, and alcohol $(\mathrm{n}=9)$ cirrhosis, 15 livers with simple steatosis, and 15 control using the western blot and quantitative real-time polymerase chain reaction and silver nitrate staining analyses, respectively.

Results. The protein levels of AMPK and pAMPK were significantly increased in all cirrhotic groups and were slightly decreased in livers with simple steatosis. The mRNA level of p53 and AgNOR features including total AgNOR number(TAN), total AgNOR length(TAL), and total AgNOR area(TAA) were significantly and simultaneously increased in tissues with NASH, PSC, and AlH cirrhosis and a significant positive correlations were observed between the mRNA level of p53 and the AgNOR features in all cirrhotic tissues.

Conclusions. The increased levels of AMPK and pAMPK could be a general response to the most common causes of liver diseases. Likely, patients with AIH, PSC, and NASH cirrhosis predispose to the development of HCC more than patients with viral and alcoholic cirrhosis.

\section{Introduction}

All patients with cirrhosis are in a premalignant condition and predispose to hepatocellular carcinoma (HCC), irrespective of etiology (1). The major causes of cirrhosis include infections (hepatitis B virus (HBV) and hepatitis $\mathrm{C}$ virus (HCV)), toxins (alcoholic fatty liver disease (AFLD)), cholestasis (Primary sclerosing cholangitis (PSC)), Autoimmune (Autoimmune hepatitis (AIH)), and metabolic (nonalcoholic fatty liver disease (NAFLD)). For several years, viral infections had been reported as the most common causes of cirrhosis but their prevalence has been decreased, mainly due to HBV vaccination (2). On the other hand, the prevalence of cholestasis, $\mathrm{AlH}$, and more specifically Non-alcoholic steatohepatitis (NASH) cirrhosis have been increased during the last decade (2-4). It has been declared that immunemediated mechanisms have a crucial role in the pathogenesis of these types of cirrhosis and among them, autoantibodies seem to be the leading findings of AlH, PSC, and NASH cirrhosis $(5,6)$. However, the exact mechanism of pathogenesis of cirrhosis and possible effects of etiologies on the pathogenesis of cirrhosis and on the progression of cirrhosis to HCC has not yet been addressed.

AMP-activated protein kinase (AMPK), a eukaryotic cellular energy sensor, is a serine/threonine kinase and has crucial role in the control of cellular homeostasis of specialized tissues including liver, muscle, and fat (7). AMPK is a highly sensitive sensor that responds to the increases in AMP content and promote 
ATP production. Alongside, it has been shown that AMPK is activated in some pathological condition, like obesity, and controls cellular homeostasis including autophagy, apoptosis, cell cycle, and cell metabolism (8). So, it is predictable that AMPK be dysregulated in these pathological conditions, such as hepatic diseases (9). It should be noted that AMPK dysregulation could be either the cause or the result of hepatic diseases. In previous studies, the tumor suppressor activity of AMPK has been declared (10). The hepatocytes with down regulation of AMPK predispose to HCC. AMPK could promote cell cycle arrest and apoptosis through multiple factors such as the p53 transcription factor (11).

The critical role of p53 in tumor suppression has been confirmed in several previous studies. However, its positive role in the regulation of the different metabolic pathways has been recognized in the more recent studies (12). In this regard, induction of the p53 has been observed in nuclei of hepatocytes of mice with fatty liver disease (13). In brief, a positive correlation has been reported between the severity of liver disease and p53 expression (14). Conversely, hepatic steatosis can develop in young p53 knock-out mice (13). There is a hypothesis that hyper-activation or loss of function of p53 can cause liver disease (15). However, like AMPK, P53 dysregulation could be either the cause or the result of hepatic diseases. In view of the fact that hepatomegaly is observed in early stages of liver diseases, the atrophic liver is one of the main characteristics of late stages of liver diseases, and also hepatomegaly occurs again during HCC development, the rate of cell proliferation and death are significantly changed during the liver disease progression. The rate of cell proliferation and death and the balance between them is represented by changes in the presence of silver stained nucleolar organizing regions (AgNOR) in the nuclei of hepatocytes and the expression of the p53, as a cell-cycle regulator and a mediator of apoptosis, in liver tissues, respectively (16). The effects of different liver disease etiology on the progression of cirrhosis to HCC have not been fully understood. Some studies have reported that patient with HCV cirrhosis have higher risk for development of HCC (17). Study of the cell proliferation and death indicators in cirrhotic patients with different etiologies could help to better understand the impact of different liver injuries on the pathogenesis and development of cirrhosis. Thus, the aim of the present study was to explore the gene expression of p53, AMPK and Pampk protein levels, as the regulators of p53, and the AgNOR features in cirrhotic livers with different etiologies, steatotic livers, as an early stage of liver disease, and controls.

\section{Experimental Procedures}

\section{Tissue samples}

A total of 68 cirrhotic liver tissue samples were collected from patients with NASH ( $n=15), H B V$ and/or HCV $(n=14), \operatorname{AlH}(n=15)$, PSC $(n=15)$, and alcohol $(n=9)$ cirrhosis at the Namazi Transplant Center, Shiraz University of Medical Sciences, Shiraz, Iran. Routinely, causes of cirrhosis are determined by an expert hepatologist team using standard diagnostic criteria at the Namazi Transplant Center. Fifteen control liver samples and 15 liver tissue samples with simple steatosis were collected from patients who underwent resection of liver metastasis at the Shiraz Central Hospital. Simple steatosis was defined as the presence of $>5 \%$ of steatosis in liver samples without inflammation and fibrosis (18). All patients 
were older than 18 years old. All liver tissue samples were divided in 2 sub-samples. One sample was frozen immediately in liquid nitrogen and stored at $-80^{\circ} \mathrm{C}$ for biochemical and molecular studies and the other part was fixed in $4 \%$ formalin and embedded in paraffin for histological assay. Using histological criteria, control tissues with abnormal histological features, steatotic tissues with abnormality other than steatosis, and cirrhotic tissues with etiologies other than the above common causes were excluded.

\section{Histological examination and AgNOR staining}

To confirm the presence of cirrhosis and determine their etiologies in cirrhotic tissues, to verify the intactness of control tissues, and also to approve liver tissue sample with steatosis, the fixed liver samples were paraffin embedded and analyzed by the hematoxylin and eosin (H\&E) staining. Silver nitrate method for AgNOR staining was done according to the method described by Bancroft and Gamble (19). The AgNOR-stained sections were examined using a light microscope (Echo Lab microscope, Italy) attached to an image analysis system (Echo Lab camera, Italy). The AgNOR examination was performed under $\times 1000$ magnification using oil immersion. Within the nucleus, AgNORs appeared as discrete black brown dots. AgNOR characterization (measuring the number, length, and area of the AgNORs) was done for at least 100 nucleus for each sample using Scion Image software (Scion, Frederick, MD).

\section{Western blot analysis}

All the frozen cirrhotic and control liver tissue samples were lysed in radioimmunoprecipitation assay buffer (RIPA buffer) with protease inhibitors (catalog no.: P8340; Sigma-Aldrich, St. Louis, M0). The amount of protein was determined using the bicinchoninic acid protein assay. Primary monoclonal antibodies AMPK (Abcam, Cambridge, MA, USA) and pAMPK (Cell Signaling Technology, Beverly, MA, USA) and a secondary antibody, horseradish peroxidase - conjugated goat anti-rabbit IgG (Abcam, Cambridge, MA, USA) were used for western blot analysis. The blots were visualized with the enhanced chemiluminescence method and were recorded on the X-ray film (Fuji, Tokyo, Japan). $\beta$-Actin was used as an internal control.

\section{Gene expression analysis by qRT-PCR}

Total RNA was extracted from frozen liver samples using the RNeasy Mini Kit (catalog no.: 74104; Qiagen, Germany) and the cDNA synthesis kit (Thermo Fisher Scientifc, Waltham, MA) was used to generate the first-strand cDNA templates. The gene expression of $p 53$ was analyzed by quantitative realtime polymerase chain reaction (qRT-PCR) (LightCycler 96 real time PCR system, Roche, Germany). The ACTB gene was used as an internal control. Primer sequences were as follows: ACTB: 5'GAGCCTCGCCTTTGCCGATCC-3' (forward) and 5'- ACATGCCGGAGCCGTTGTCG-3' (reverse), p53: 5'AGAGGAAGAGAATCTCCGCAAG-3' (forward) and 5'- TTGGGCAGTGCTCGCTTAG-3' (reverse). qRT-PCR was done in triplicate. Relative changes in gene expression were determined using the $2^{-\triangle C T}$ method.

\section{Statistical analysis}

Data analysis was done with the SPSS software version 16.0 (SPSS, Inc., Chicago, IL). The results of AgNOR staining, western blot analyses, and qRT-PCR in cirrhotic livers were compared with those of 
controls using one-way analysis of variance (ANOVA) and the independent $t$ test. The Kruskal-Wallis and Mann-Whitney $\mathrm{U}$ tests were also used for analyzing the data with abnormal distributions. The distribution of the data was examined by the Shapiro-Wilk test. The Spearman correlation coefficient was used to examine the relationship between the study parameters. Results were expressed as mean \pm standard error of the mean (mean \pm SEM), and $p<0.05$ was considered statistically significant.

\section{Results}

In the present study all samples were approved by pathological examinations as the gold standard method. Demographic and clinical features of the study subjects are summarized in Table 1.

Table 1

Demographic and clinical features of the patients with NASH, PSC, alcoholic, AlH, and HBV/HCV cirrhosis, simple steatosis and control

\begin{tabular}{|llllllll|}
\hline & $\begin{array}{l}\text { Control } \\
\text { subjects }\end{array}$ & $\begin{array}{l}\text { Simple } \\
\text { steatosis }\end{array}$ & $\begin{array}{l}\text { NASH } \\
\text { cirrhosis }\end{array}$ & $\begin{array}{l}\text { PSC } \\
\text { cirrhosis }\end{array}$ & $\begin{array}{l}\text { AlH } \\
\text { cirrhosis }\end{array}$ & $\begin{array}{l}\text { Alcoholic } \\
\text { cirrhosis }\end{array}$ & $\begin{array}{l}\text { HBV/HCV } \\
\text { cirrhosis }\end{array}$ \\
\hline $\begin{array}{l}\text { No. of } \\
\text { subjects }\end{array}$ & 15 & 15 & 15 & 15 & 15 & 9 & 14 \\
$\begin{array}{l}\text { Sex } \\
\text { (male/female) }\end{array}$ & $9 / 6$ & $4 / 11$ & $9 / 6$ & $5 / 10$ & $4 / 11$ & $8 / 1$ & $9 / 5$ \\
\hline Age (year) & $43.2 \pm$ & $44.11 \pm$ & $51.66 \pm$ & $37.4 \pm$ & $33.13 \pm$ & $36.33 \pm$ & $53.64 \pm$ \\
& 9.16 & 9.32 & 10.31 & 11.78 & 11.5 & 9.3 & 8.9 \\
\hline BMI (kg/m ${ }^{2}$ ) & $22.75 \pm$ & $30.39 \pm$ & $29.05 \pm$ & $26.1 \pm$ & $24.4 \pm$ & $28.5 \pm$ & $26.15 \pm$ \\
& 3.27 & 4.36 & 3.39 & 4.3 & 3.9 & 5.2 & 4.8 \\
\hline MELD score & - & - & $22.33 \pm$ & $18.33 \pm$ & $21.3 \pm$ & $\begin{array}{l}30.2 \pm \\
6.7\end{array}$ & $23.2 \pm 7$ \\
\hline
\end{tabular}

\section{The levels of AMPK and pAMPK were increased in human liver tissues with cirrhosis}

The results of the present study showed that the protein level of AMPK was significantly increased in all cirrhotic liver tissues with different etiologies as compared to control group and the increase was greater in livers with HBV/HCV cirrhosis (Fig. 1A). Alongside, the protein level of pAMPK was significantly increased in all of the cirrhotic groups, more especially in livers with HBV/HCV cirrhosis and with the exception of AlH cirrhosis (Fig. 1B). Interestingly, the protein levels of AMPK and PAMPK in liver tissues with simple steatosis were lower, but not significant as compared with those of control group (Fig. 1C and 1D). 


\section{Does the etiology of cirrhosis affect the p53 gene expression?}

The mRNA level of p53 was significantly increased only in tissues with NASH, PSC, and AlH cirrhosis as compared to control group (Fig. 2A). Also, p53 gene expression in tissues with simple steatosis had not significant difference with that in control (Fig. 2B). Despite the expectation, there was no significant correlation between the protein levels of AMPK and p-AMPK and the mRNA level of p53 in all cirrhotic tissues.

\section{AgNOR features were completely in agreement with p53 gene expression}

AgNOR staining results showed that total AgNOR number (TAN), total AgNOR length (TAL), and total AgNOR area (TAA) in tissues with NASH, PSC, and AlH cirrhosis were significantly higher than those of control and there was no significant difference between tissues with alcoholic and HBV/HCV cirrhosis and control (Figs. 3A, 3C, 3E). Also, AgNOR features were analyzed in tissues with simple steatosis and it was observed that AgNOR features were similar to that of control group (Figs. 3B, 3D, 3F). Unlike the protein levels of AMPK and p-AMPK, statistically significant positive correlations were observed between the mRNA level of p53 and the AgNOR features in all cirrhotic tissues (Fig. 4).

\section{Discussion}

To date, several reasons have been reported for liver diseases and cirrhosis including viral infection, cholestasis, metabolic diseases, alcohol, and autoimmune disease. In most of these cases, the exact mechanism of liver injury has not been completely understood. At the same time, there are considerable patients with unknown cirrhosis etiology despite extensive investigations (named cryptogenic cirrhosis). On the other hand, all patients with cirrhosis predispose to HCC. Accordingly, in the present case-control study, p53 gene expression, as a cell-cycle regulator and a mediator of apoptosis, the protein levels of AMPK and pAMPK, as p53 regulators, AgNOR features, as the cell proliferation indicators, and their correlations were studied in cirrhotic tissues with different etiologies. Also, due to the role of p53, AMPK, and PAMPK in metabolic pathways, the factors were analyzed in tissues with simple steatosis.

In previous studies, the protective role of AMPK has been confirmed against liver fibrosis (20-22). In the present study, AMPK and pAMPK levels were increased in cirrhotic patients and the increase was more pronounced in patients with viral hepatitis. According to the study results, two questions arise: one, why does fibrosis occur despite the AMPK upregulation and activation. Second, causes of liver diseases how do affect the AMPK expression and activation? Probably, liver cells increase AMPK expression and activation in response to injuries, but due to the high severity and long duration of injuries, it cannot prevent the development of fibrosis. However, the effects of different causes of liver disease on AMPK expression and activation and also liver fibrosis development has not been declared despite extensive 
study of AMPK in liver disease with different etiologies. A brief review of the previous studies revealed that AMPK affects the development of liver fibrosis in most patients, more specifically in patients with $\mathrm{HCV}$ infection and fatty liver diseases. It has been reported that AMPK decreases fibrotic gene expression in HCV-infected cells (22). Other studies have shown that HCV core protein could affects the activity of AMPK and HCV genome replication decreases AMPK phosphorylation $(23,24)$. Also, HCV genome replication is increased through inhibition of AMPK and HCV genome replication is decreased through activation of AMPK $(12,25)$. On the other hand, it has been shown that AMPK signaling pathway inhibits liver fibrosis induced by alcohol and controls liver injuries in patients with $\operatorname{NASH}(20,26)$. So, increased AMPK expression in liver tissues could be a general response to the most common causes of liver diseases and also the increase may be partially affected by some of liver disease etiology such as viral hepatitis and fatty liver. Interestingly, we also observed that AMPK and PAMPK levels were decreased, but not significant, in liver tissues with simple steatosis. Previous studies have shown that many of the suggested therapeutics available for the NAFLD increase the activity of the AMPK (27). Also, AMPK activation in liver tissue leads to reduced steatosis (28). Thus, steatosis may be induced in tissues with simple steatosis by AMPK downregulation and inactivation.

Regarding the promotion of cell cycle arrest and apoptosis by AMPK through p53, it was expecting that p53 gene expression have a significant positive correlation with AMPK and pAMPK levels in cirrhotic patients, but there was no significant correlation between them. As postulated in previous studies, p53 expression and its activity is regulated by several mechanisms and our finding declare that p53 gene expression is mainly dependent on mechanisms other than AMPK signaling pathway in patients with cirrhosis (29). Meanwhile, it was observed that p53 gene expression may be affected by the cause of liver disease so that only patients with AlH, PSC, and NASH cirrhosis had significantly higher gene expression of p53 compared to that of the control group. On the other hand, similar to the p53 gene expression, AgNOR features were significantly increased only in patients with AlH, PSC, and NASH cirrhosis. Also, AgNOR features had significant positive correlations with the mRNA level of p53 in cirrhotic tissues. These findings propose that patients with AlH, PSC, and NASH cirrhosis predispose to HCC. Epidemiologic studies have reported that HBV and HCV infections and also alcohol abuse are the leading risk factors for HCC because a considerable percentage of patients with HCC have HBV and/or HCV infections or have heavy alcoholism $(30,31)$. However, it should be noted that HBV, HCV, and alcohol are the leading causes of cirrhosis in several countries $(3,32,33)$. Furthermore, due to the development of specific laboratory tests for HBV and HCV infections and also easy diagnosis of alcohol consumption, most of the patients with HBV-, HCV-, and alcohol related cirrhosis are definitely diagnosed. On the other hand, there was not any definitive criteria or laboratory tests for diagnosis of $\mathrm{AlH}, \mathrm{NASH}$, and PSC cirrhosis. Thus, it is likely that considerable percentage of AlH, NASH, and PSC patients have not been diagnosed and named as cryptogenic. Also, autoimmune diseases play important role in the pathogenesis of $\mathrm{AlH}, \mathrm{NASH}$, and PSC cirrhosis and their progression to $\mathrm{HCC}(34,35)$. Moreover, progression of NASH to HCC without cirrhosis has been reported (36). So, it is reasonable that their pathogenesis have similar features. Therefore, it is possible that patients with $\mathrm{AlH}, \mathrm{NASH}$, and PSC cirrhosis predispose to the development of HCC more than viral and alcohol cirrhosis. However, more 
studies are needed to confirm this claim. Also, AgNOR features and p53 gene expression in tissues with simple steatosis were similar to those of control group. These findings suggest that cell proliferation and apoptosis rates are not changed in patients with simple steatosis.

In conclusion, it was shown that the AMPK and PAMPK expression increase in cirrhotic liver tissues and it could be a general response to the most common causes of liver diseases. Also, downregulation of AMPK and pAMPK may be an important mechanism of liver steatosis. p53 gene expression increase in patients with cirrhosis in an etiology-dependent manner but independent of AMPK signaling pathway. Similar to the p53 gene expression, AgNOR features were significantly increased only in patients with AlH, PSC, and NASH cirrhosis and had positive correlation with p53 gene expression. Therefore, it is possible that these patients predispose to the development of HCC more than patients with viral and alcohol cirrhosis.

\section{Declarations}

Funding: This work was supported by the Hamadan University of Medical Sciences (grant number: 9910307697).

Competing Interests: The authors have no relevant financial or non-financial interests to disclose.

Conflict of Interest: The authors declare that there are no conflicts of interest.

Ethical approval: All of the procedures were performed in accordance with the 1964 Helsinki Declaration and its later amendments or comparable ethical standards and with the ethical standards of the institutional and/or national research committee. The Research Ethics Committee of the Hamadan University of Medical Sciences approved the study (approval number: IR.UMSHA.REC.1399.705).

Informed consent: The aim of the present study was explained to patients and written informed consent was obtained from all participants.

\section{References}

1. Fattovich G, Stroffolini T, Zagni I, Donato F. Hepatocellular carcinoma in cirrhosis: incidence and risk factors. Gastroenterology. 2004;127(5):35-50.

2. Mohagheghi S, Khajehahmadi Z, Nikeghbalian S, Alavian SM, Doosti-Irani A, Khodadadi I, et al. Changes in the distribution of etiologies of cirrhosis among patients referred for liver transplantation over 11 years in Iran. Eur J Gastroenterol Hepatol 2020;32(7):844-50.

3. Wang X, Lin S-X, Tao J, Wei X-Q, Liu Y-T, Chen Y-M, et al. Study of liver cirrhosis over ten consecutive years in Southern China. World J Gastroenterol. 2014;20(37):13546.

4. Boonstra K, Beuers U, Ponsioen CY. Epidemiology of primary sclerosing cholangitis and primary biliary cirrhosis: a systematic review. J Hepatol. 2012;56(5):1181-8. 
5. Parthasarathy G, Revelo X, Malhi H. Pathogenesis of nonalcoholic steatohepatitis: an overview. Hepatol Commun. 2020;4(4):478-92.

6. Pollheimer MJ, Halilbasic E, Fickert $P$, Trauner M. Pathogenesis of primary sclerosing cholangitis. Best Pract Res Clin Gastroenterol. 2011;25(6):727-39.

7. Kahn BB, Alquier T, Carling D, Hardie DG. AMP-activated protein kinase: ancient energy gauge provides clues to modern understanding of metabolism. Cell Metab. 2005;1(1):15-25.

8. Zheng L, Yang W, Wu F, Wang C, Yu L, Tang L, et al. Prognostic significance of AMPK activation and therapeutic effects of metformin in hepatocellular carcinoma. Clin Cancer Res. 2013;19(19):5372-80.

9. Smith BK, Marcinko K, Desjardins EM, Lally JS, Ford RJ, Steinberg GR. Treatment of nonalcoholic fatty liver disease: role of AMPK. Am J Physiol-Endocrinol Metab. 2016;311(4):E730-E40.

10. Jones RG, Plas DR, Kubek S, Buzzai M, Mu J, Xu Y, et al. AMP-activated protein kinase induces a p53dependent metabolic checkpoint. Mol Cell. 2005;18(3):283-93.

11. Lee C-W, Wong LL-Y, Tse EY-T, Liu H-F, Leong VY-L, Lee JM-F, et al. AMPK promotes p53 acetylation via phosphorylation and inactivation of SIRT1 in liver cancer cells. Cancer Res. 2012;72(17):4394404.

12. Berkers CR, Maddocks OD, Cheung EC, Mor I, Vousden KH. Metabolic regulation by p53 family members. Cell Metab. 2013;18(5):617-33.

13. Wang X, Zhao X, Gao X, Mei Y, Wu M. A new role of p53 in regulating lipid metabolism. J Mol Cell Biol. 2013;5(2):147-50.

14. Panasiuk A, Dzieciol J, Panasiuk B, Prokopowicz D. Expression of p53, Bax and Bcl-2 proteins in hepatocytes in non-alcoholic fatty liver disease. World J Gastroenterol. 2006;12(38):6198.

15. Krstic J, Galhuber M, Schulz TJ, Schupp M, Prokesch A. p53 as a dichotomous regulator of liver disease: the dose makes the medicine. Int J Mol Sci. 2018;19(3):921.

16. Munda M, Hajdinjak T, Kavalar R, Martinčič DŠ. p53, Bcl-2 and AgNOR tissue markers: model approach in predicting prostate cancer characteristics. J Int Med Res. 2009;37(6):1868-76.

17. Ioannou GN, Green P, Lowy E, Mun EJ, Berry K. Differences in hepatocellular carcinoma risk, predictors and trends over time according to etiology of cirrhosis. PloS one. 2018;13(9):e0204412.

18. Kleiner DE, Brunt EM, Van Natta M, Behling C, Contos MJ, Cummings OW, et al. Design and validation of a histological scoring system for nonalcoholic fatty liver disease. Hepatology. 2005;41(6):131321.

19. Bancroft JD, Gamble M. Theory and practice of histological techniques. 5 ed. Philadelphia, PA: Churchill Livingstone Elsevier; 2002.

20. Zhao P, Sun X, Chaggan C, Liao Z, in Wong K, He F, et al. An AMPK-caspase- 6 axis controls liver damage in nonalcoholic steatohepatitis. Science. 2020;367(6478):652-60.

21. Wang Y, Li C, Gu J, Chen C, Duanmu J, Miao J, et al. Celastrol exerts anti-inflammatory effect in liver fibrosis via activation of AMPK-SIRT3 signalling. J Cell Mol Med. 2020;24(1):941-53. 
22. Jung GS, Jeon JH, Choi YK, Jang SY, Park SY, Kim MK, et al. Small heterodimer partner attenuates profibrogenic features of hepatitis C virus-infected cells. Liver Int. 2015;35(10):2233-45.

23. Sun L-J, Yu J-W, Wan L, Zhang X-Y, Shi Y-G, Chen M-Y. Endocannabinoid system activation contributes to glucose metabolism disorders of hepatocytes and promotes hepatitis $C$ virus replication. Int J Infect Dis. 2014;23:75-81.

24. Yu J-W, Sun L-J, Liu W, Zhao Y-H, Kang P, Yan B-Z. Hepatitis C virus core protein induces hepatic metabolism disorders through down-regulation of the SIRT1-AMPK signaling pathway. Int J Infect Dis. 2013;17(7):e539-e45.

25. Mankouri J, Tedbury PR, Gretton S, Hughes ME, Griffin SD, Dallas ML, et al. Enhanced hepatitis C virus genome replication and lipid accumulation mediated by inhibition of AMP-activated protein kinase. Proc Natl Acad Sci. 2010;107(25):11549-54.

26. Wan T, Wang S, Ye M, Ling W, Yang L. Cyanidin-3-O- $\beta$-glucoside protects against liver fibrosis induced by alcohol via regulating energy homeostasis and AMPK/autophagy signaling pathway. J Funct Foods. 2017;37:16-24.

27. Smith BK, Marcinko K, Desjardins EM, Lally JS, Ford RJ, Steinberg GR. Treatment of nonalcoholic fatty liver disease: role of AMPK. Am J Physiol Endocrinol Metab. 2016;311(4):E730-E40.

28. Garcia D, Hellberg K, Chaix A, Wallace M, Herzig S, Badur MG, et al. Genetic liver-specific AMPK activation protects against diet-induced obesity and NAFLD. Cell Rep. 2019;26(1):192-208. e6.

29. Hafner A, Bulyk ML, Jambhekar A, Lahav G. The multiple mechanisms that regulate p53 activity and cell fate. Nat Rev Mol Cell Biol. 2019;20(4):199-210.

30. Wu J. The changing epidemiology of hepatocellular carcinoma in Asia versus United States and Europe. Adv mod oncol res. 2017;3(s1):51-8.

31. Chen C, An L, Cheng Y, Luo X, Li Z, Liu X. Clinical Outcomes and Prognosis Factors of Nivolumab Plus Chemotherapy or Multitarget Tyrosine Kinase Inhibitor in Multi-Line Therapy for Recurrent Hepatitis B Virus-Related Hepatocellular Carcinoma: A Retrospective Analysis. Front Oncol. 2020;10:1404.

32. Sharma B, Marwah R, Raina S, Sharma N, Kaushik M, Kaushal SS. A study on the etiology of cirrhosis of liver in adults living in the Hills of Himachal Pradesh, India. Trop gastroenterol. 2017;37(1):37-41.

33. Mittal S, El-Serag HB. Epidemiology of HCC: consider the population. J Clin Gastroenterol. 2013;47:S2.

34. Gidwaney NG, Pawa S, Das KM. Pathogenesis and clinical spectrum of primary sclerosing cholangitis. World J Gastroenterol. 2017;23(14):2459.

35. Barrow F, Khan S, Wang H, Revelo XS. The Emerging Role of B Cells in the Pathogenesis of NAFLD. Hepatology. 2021.

36. Anstee QM, Reeves HL, Kotsiliti E, Govaere O, Heikenwalder M. From NASH to HCC: current concepts and future challenges. Nat Rev Gastroenterol Hepatol. 2019;16(7):411-28. 
A
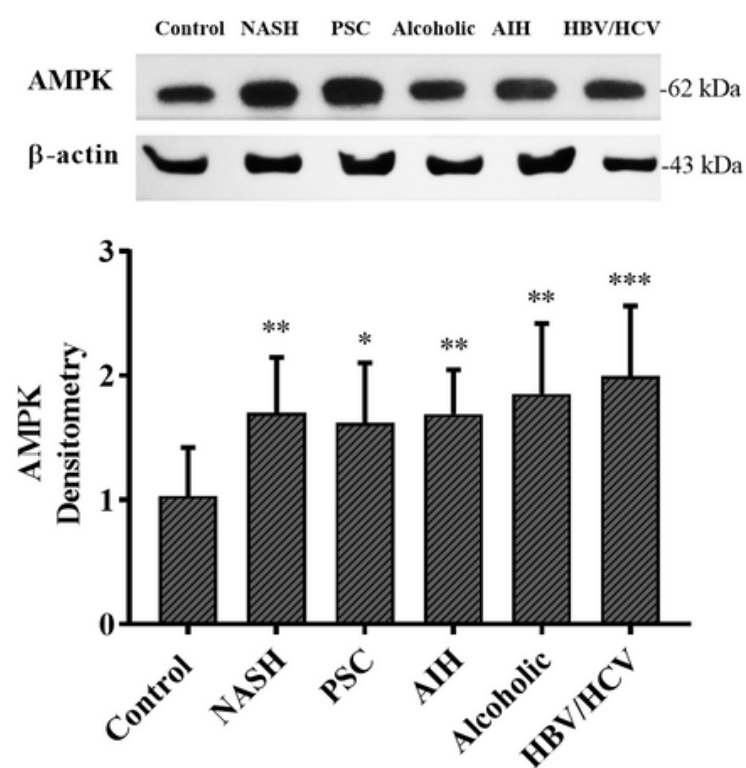

C
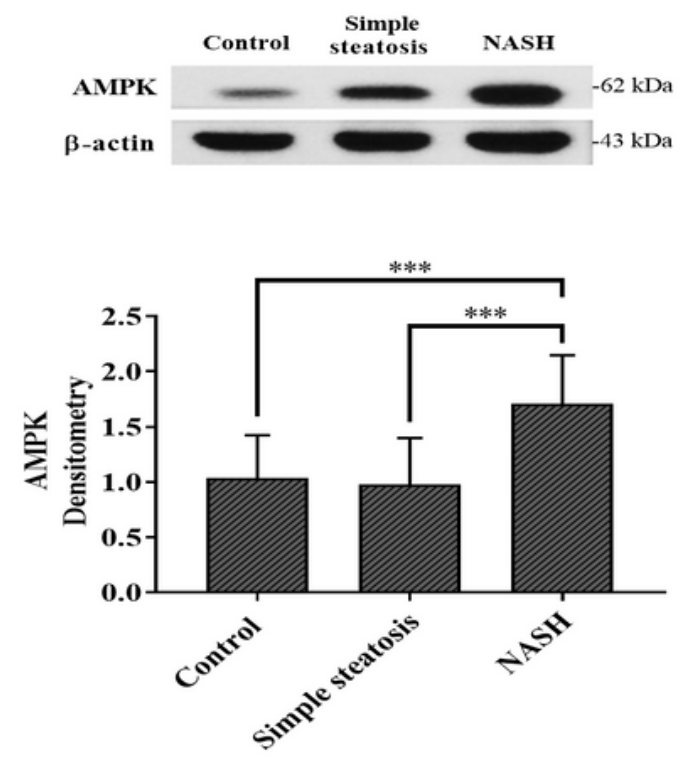

B
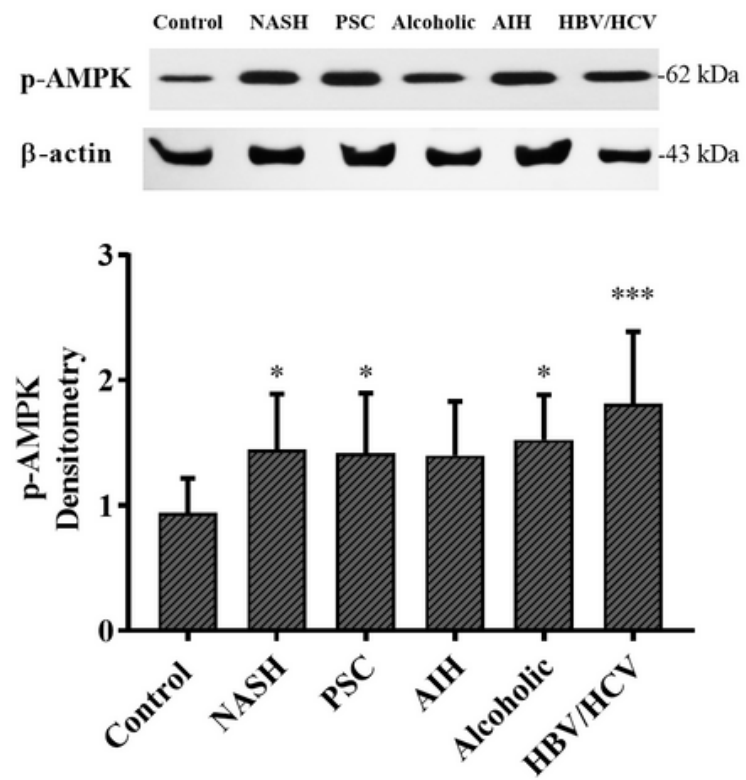

D
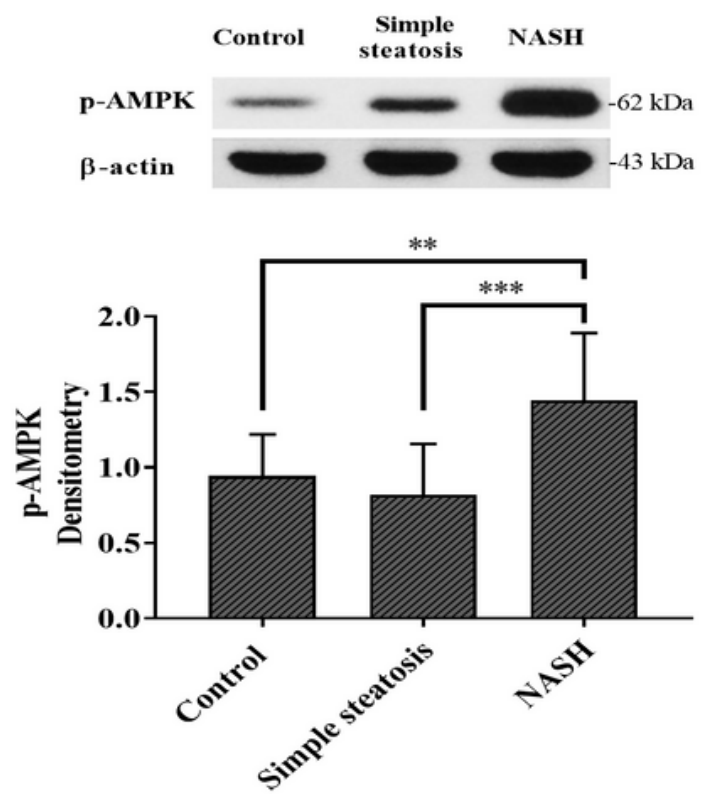

\section{Figure 1}

(A and B) AMPK and pAMPK protein levels in liver tissues with NASH $(n=15), \operatorname{PSC}(n=15)$, alcoholic $(n=$ $9), A l H(n=15)$, and HBV/HCV cirrhosis $(n=14)$ and control $(n=15)$. ( $C$ and $D)$ AMPK and pAMPK protein levels in liver tissues with NASH cirrhosis $(n=15)$, Simple steatosis $(n=15)$, and control $(n=15)$. 
Western blotting bands are representative of one sample per group for each group. The band intensity was quantified densitometrically using the ImageJ software (National Institutes of Health, Bethesda, $M D)$. Western blotting results were normalized to $\beta$-actin and are displayed as the mean \pm SEM. $\left({ }^{*} p<.05\right.$; $\star \star p<.01 ;$ and ${ }^{* \star *} \mathrm{p}<.001$ vs. control).

$\mathrm{AlH}$, autoimmune hepatitis; $\mathrm{HBV}$, hepatitis B virus; and $\mathrm{HCV}$, hepatitis $\mathrm{C}$ virus; $\mathrm{NASH}$, nonalcoholic steatohepatitis; PSC, primary sclerosing cholangitis.

$\mathbf{A}$

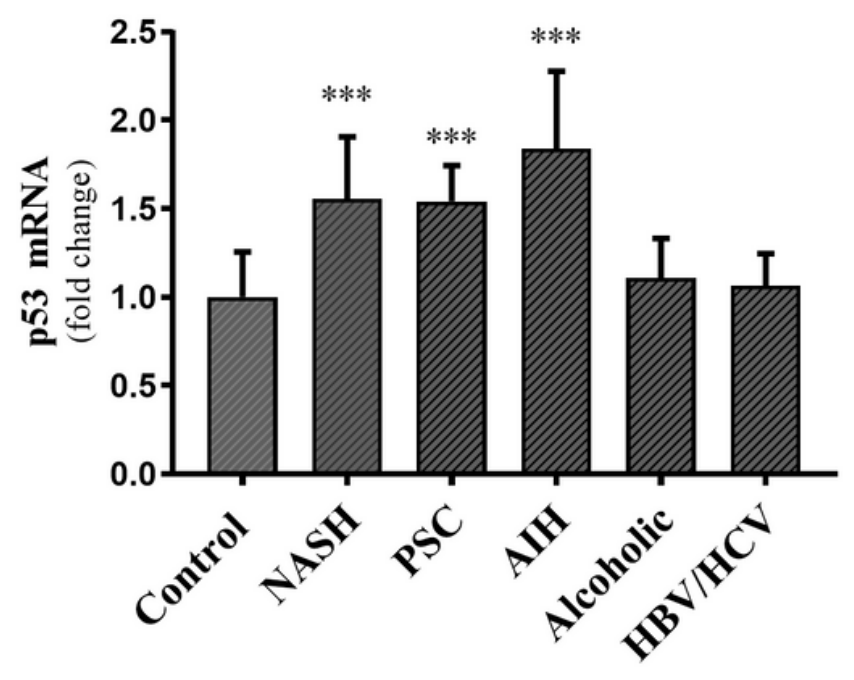

$\mathbf{B}$

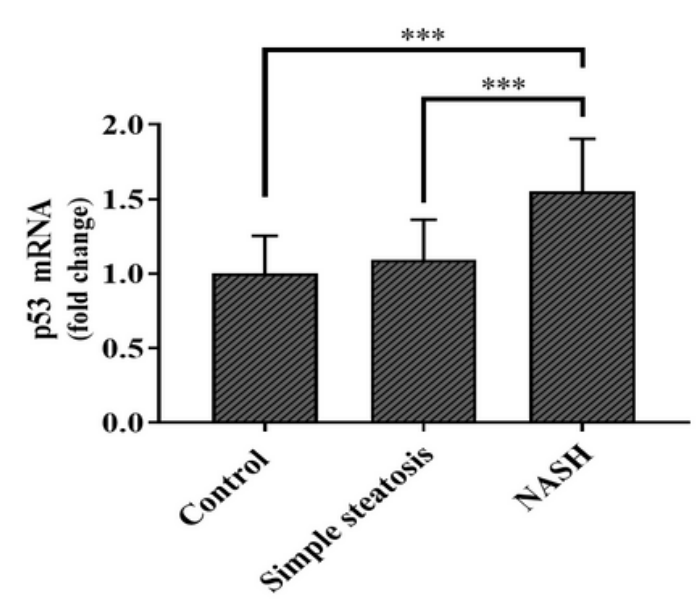

Figure 2

(A) mRNA levels of p53 in liver tissues with NASH $(n=15), \operatorname{PSC}(n=15)$, alcoholic $(n=9)$, AlH $(n=15)$, and HBV/HCV cirrhosis $(n=14)$ and control $(n=15)$. (B) mRNA levels of p53 in liver tissues with NASH cirrhosis $(n=15)$, Simple steatosis $(n=15)$, and control $(n=15)$. $\beta$-actin was used as the housekeeping gene. Results are displayed as fold change relative to control livers and are expressed as the mean \pm SEM. $\left({ }^{\star} p<.05 ; * \star p<.01\right.$; and ${ }^{* \star *} p<.001$ vs. control).

AlH, autoimmune hepatitis; $\mathrm{HBV}$, hepatitis $\mathrm{B}$ virus; and $\mathrm{HCV}$, hepatitis $\mathrm{C}$ virus; $\mathrm{NASH}$, nonalcoholic steatohepatitis; PSC, primary sclerosing cholangitis. 
A

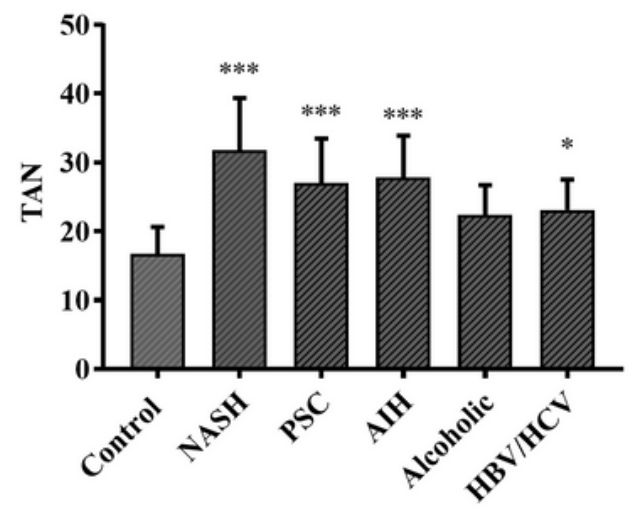

C

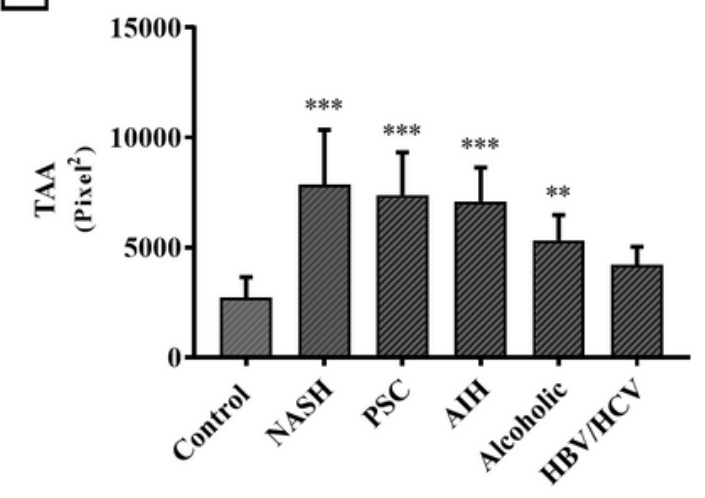

E

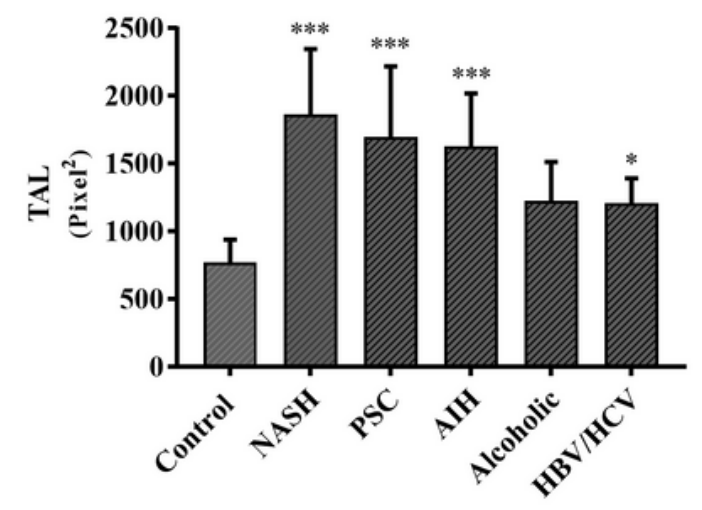

B

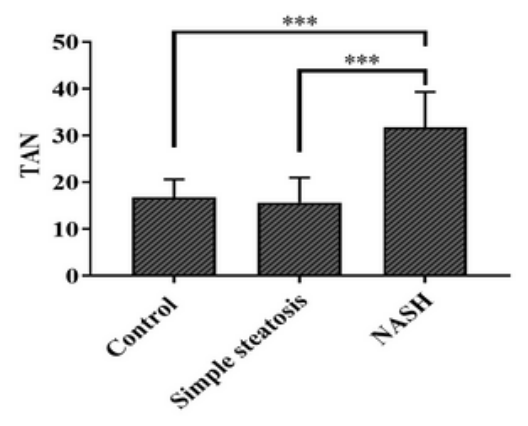

D

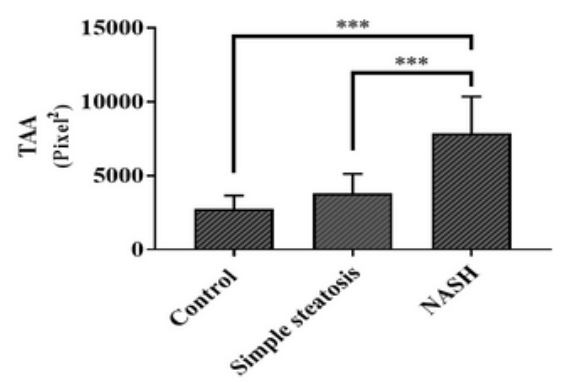

F

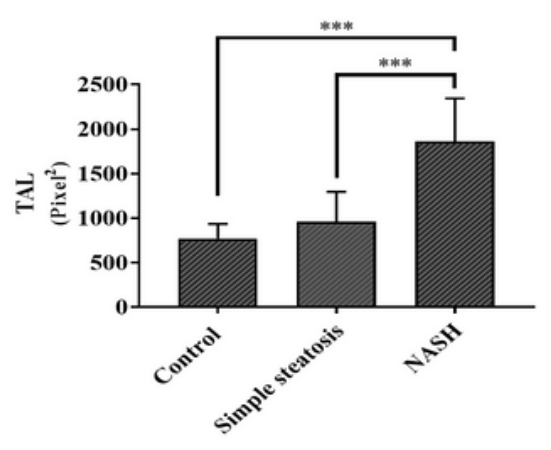

\section{Figure 3}

(A, C, and E) AgNOR features including TAN, TAL, and TAA in liver tissues with NASH $(n=15)$, PSC $(n=$ $15)$, alcoholic $(n=9)$, AlH $(n=15)$, and HBV/HCV cirrhosis $(n=14)$ and control $(n=15)$. (B, D, and F) AgNOR features in liver tissues with NASH cirrhosis $(n=15)$, Simple steatosis $(n=15)$, and control $(n=$ 15). Results are expressed as the mean \pm SEM. $\left({ }^{\star} p<.05 ;{ }^{* \star} p<.01\right.$; and ${ }^{\star \star *} p<.001$ vs. control). 
TAN, total AgNOR number; TAL, total AgNOR length; TAA, total AgNOR area; AlH, autoimmune hepatitis; $\mathrm{HBV}$, hepatitis B virus; and HCV, hepatitis C virus; NASH, nonalcoholic steatohepatitis; PSC, primary sclerosing cholangitis.
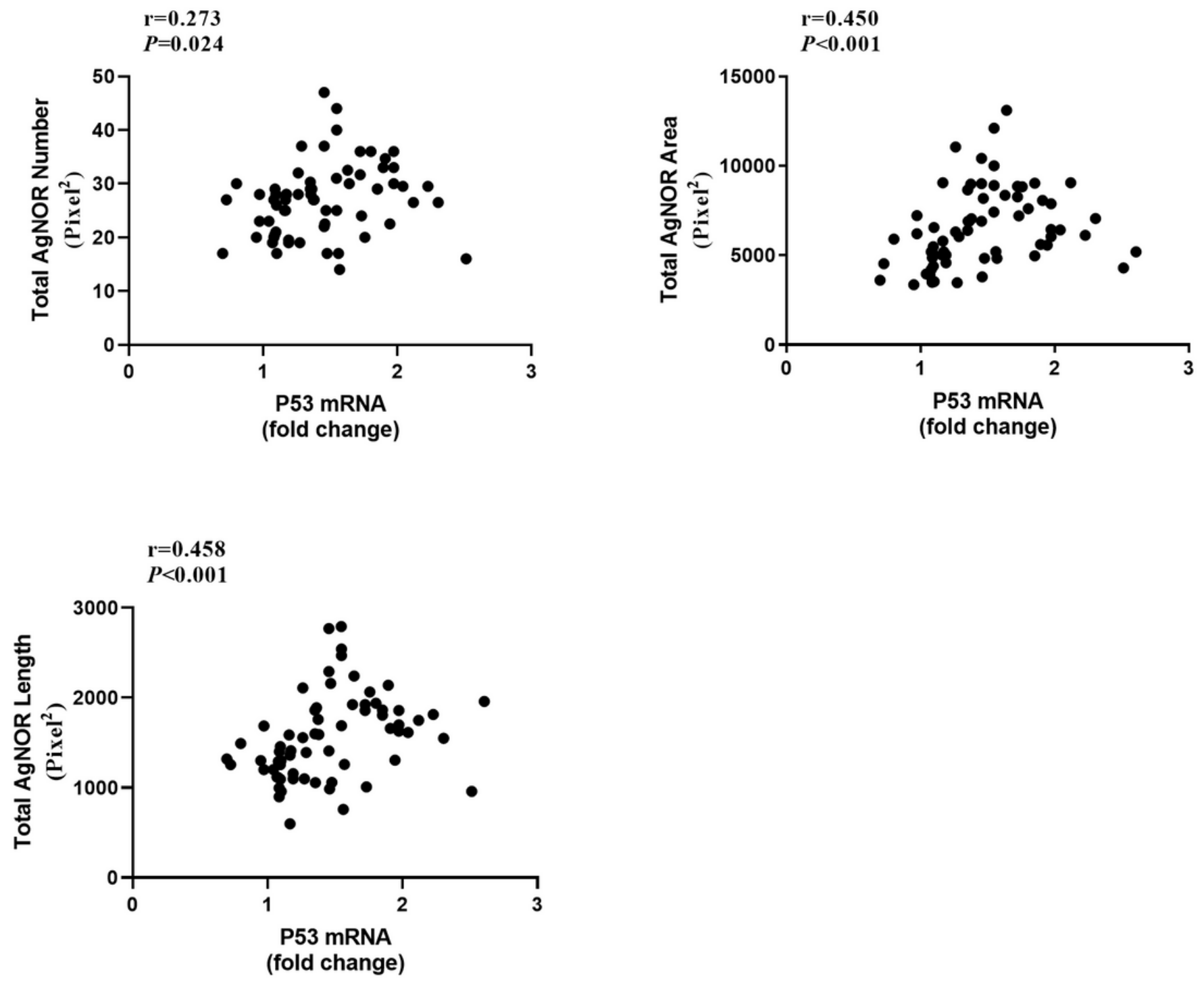

Figure 4

Correlations of P53 mRNA fold change with AgNOR features including TAN, TAL, and TAA in patients with cirrhosis.

TAN, total AgNOR number; TAL, total AgNOR length; TAA, total AgNOR area 